\title{
Campeões de bilheteria e o sucesso como antídoto ao terceiro
}

\section{Blockbusters and sucess as the antidote for the third}

Ana Taís Portanova Barros ${ }^{1}$ 


\section{Resumo}

Este trabalho se propõe a refletir sobre as condições simbólicas (Durand, Bachelard) que, no cinema, podem participar da imagem do sucesso a qual, considerada no que exige de consenso e adesão coletiva, é definida a partir da premissa dos estudos do imaginário sobre as representações dos princípios lógicos de antítese, analogia e complexidade, ponderando-se que a relação com a diferença é fundamental para compreender a condição simbólica do sucesso. Com essa premissa, são examinados três dos dez filmes considerados os maiores sucessos (de bilheteria) de todos os tempos: ...E o vento levou, Avatar e Titanic. Conclui-se que tanto em Avatar quanto em Titanic existe uma abordagem dualista da alteridade. Já em ...E o vento levou, a abordagem é monista. Em quaisquer dos casos, é escamoteada a pluralidade, com a recusa da efetividade do Outro enquanto terceiro.

Palavras-chave

Imaginário, comunicação, cinema, sucesso.

\section{Abstract}

This work aims to reflect on the symbolic conditions (Durand, Bachelard) that, in the cinema, can take part of the image of success. This, considered in its requirements of consensus and collective adhesion, is defined from the premise of the Imaginary Studies on the representations of the logical principles of antithesis, analogy and complexity, pondering that the relation with the difference is fundamental to understand the symbolic condition of success. With this premise, three of the ten films considered the greatest box-office hits of all time are analyzed: ...Gone with the wind, Avatar and Titanic. It is concluded that in both Avatar and Titanic there is a dualistic approach to otherness, while in ...Gone with the wind the approach is monistic. In either case, plurality is retracted, with the refusal of the Other's effectiveness as a third party.

\section{Keywords}

Imaginary, communication, cinema, success. 


\title{
Sucesso, imagem simbólica
}

Algumas arrecadações no cinema, como aquelas de certas bilheterias, são tão grandiosas que se tornam difíceis de imaginar. Três bilhões de dólares por Avatar, quase o mesmo por Titanic; 6 bilhões de dólares por ...E o vento levou. Nesse último caso, são quase 700 milhões de pessoas que viram o filme; 350 milhões nos outros dois². O que move multidões como essas?

Já pelo menos desde Morin (1997, p. 113-114), que, em 1956 publicou a primeira edição de Le Cinéma ou l'Homme Imaginaire ${ }^{3}$, o encanto do cinema encontra explicação no fenômeno da projeção/identificação que proporciona:

\begin{abstract}
A projecção-identificação (participação afectiva) desempenha continuamente o seu papel na nossa vida quotidiana, privada e social. [...] Na medida em que identificamos as imagens do ecrã com a vida real, as nossas projecções-identificações próprias da vida real põem-se em movimento. [...] No ecrã, há apenas jogos de sombra e luz; só num processo de projecção é possível identificar as sombras com coisas e seres reais e atribuir-Ihes essa realidade que tão evidentemente lhes falta [...]. Em outras palavras, há um mecanismo de projecção-identificação na origem da percepção cinematográfica.
\end{abstract}

O princípio da identificação preside também algumas estruturas mitológicas, chegando mesmo a levar à sua hipostasia em certas vertentes de estudo, capitaneadas, talvez, pelo conceito de monomito erigido por Campbell nos anos 1940 (em O herói de mil faces) e por ele sustentado ao longo de sua obra. Segundo essa vertente, o personagem principal de uma narrativa mítica seria, de modo mais ou menos explícito, um herói; seu destino seria percorrer uma série de etapas cujos detalhes podem variar fenomenicamente, mas são constantes de forma arquetipológica. Mesclando a noção junguiana de arquétipo com uma visão estruturalista dos mitos, Campbell (2007) chega à definição de três grandes blocos de ações comuns a essas narrativas: a partida, com a resistência e a perplexidade 
iniciais do herói, que sucumbe a um chamado inescapável; a iniciação, com suas provas e dificuldades aparentemente insuperáveis culminando na vitória; o retorno, quando o herói novamente opõe resistência ao apelo sobrenatural, mas acaba aceitando-o e se tornando, finalmente, livre, dominando tanto o cotidiano prosaico quanto a exceção heroica. Esse esquema, centrado na questão da identidade, conhece aplicações desde a educação (GOLDSTEIN, 2005) até os estudos étnicos (HAMILTON, 2007), da literatura (MCDONALD, 1991) à psicologia (CLIFT; CLIFT, 1988). No entanto, na área da Comunicação a mais conhecida das aplicações do esquema tem sido aquela feita aos roteiros de Hollywood (VOGLER, 1996), constituindo uma fórmula que não só comandou a produção de filmes dos estúdios Disney durante os dez anos seguintes à sua elaboração, como também se tornou paradigma explicativo de sucessos anteriores e posteriores.

Hoje, detecta-se nos estudos do imaginário uma consensualidade em usar o princípio identitário para elucidar o fascínio das multidões por certas imagens colocadas em circulação pela mídia. No Brasil, o trabalho fundante nesse sentido é de Fischer (1982). Buscando os porquês do encanto da televisão nas crianças e adolescentes no final da década de 1970, a autora verificou uma vivência eletrônica do mito na participação em narrativas que,

[...] explicitamente ou não, falam de questões fundamentais para o homem, relacionadas com indagações sobre a origem da espécie humana, o eterno medo da morte, do desconhecido e do anormal, e o desejo de dominar o tempo e de viver o sonho da eterna felicidade (FISCHER, 1982, p. vi).

Seria tentador - com base na ideia de que nada nos interessa mais do que nós mesmos, de que tudo o que desejamos é aprender, através dos outros, a conduzir nossa própria vida e a compreender nosso papel no mundo - buscarem-se analogias das narrativas bem-sucedidas para o grande público com mitologias de iniciação, notadamente mitologias de heróis e, dentro desse escopo, com o já mencionado esquema de jornada do herói desenhado por Campbell (2007). No entanto, utilizada esquematicamente, a ideia de monomito leva à estereotipia na análise, deixa esquecer que os heróis míticos são, antes de tudo, seres atormentados, amaldiçoados 
pela missão que Ihes é conferida, cruéis, arrastados quase sempre a um destino terrível. Talvez, por isso, as correntes teóricas que encontram nesses mitos uma estrutura capaz de redimir a existência humana precisem, para tanto, reter apenas os mitemas gloriosos, valorizados, evidentemente, pela dor e pelo sacrifício, mas que redundam na redenção final, na paz eterna que traria o autoconhecimento.

Não se trata aqui de explorar as consequências das usuras e desgastes dos mitos (DURAND, 1996) que os afastam de seu potencial subversivo, mas também são o recurso pelo qual sua sobrevivência no tempo e nas culturas é garantida. Sacralização, dessacralização e ressacralização nos processos de Comunicação têm recebido atenção dos estudos do imaginário (BARROS, 2016; WUNENBURGER, 2017) e precisam, ainda, de mais investigação. Retomaremos brevemente, mais adiante, a correlação do medo ao diverso com a sacralidade, detendo-nos, no entanto, na circunstância em que o diverso não é um mistério, e sim possui aspectos suficientemente conhecidos para que se possam estabelecer semelhanças e dessemelhanças com o Mesmo; em suma, imagens da alteridade que ladeiam ou constelam as do sucesso.

\section{O um, o outro e o terceiro}

Na mitologia, é a iniciação que indica pistas para responder à pergunta fundante da identidade, quem sou eu? Se é pelo outro que se conhece a si mesmo, reciprocamente é o autoconhecimento que estabelece o diverso. Morin (1997, p. 127) detecta no cinema uma manifestação desse jogo entre identidade e alteridade:

Joga não só com o herói à minha semelhança, mas também com o herói à minha dissemelhança: ele, simpático, aventureiro, vivo e alegre, eu macambúzio, prisioneiro, funcionário. Pode também jogar a favor do criminoso ou do fora da lei, se bem que a digna antipatia das pessoas honestas o reprove, mal ele cometa o acto que Ihes satisfaz os seus desejos mais profundos. O filme excita, assim, tanto uma identificação com o semelhante como uma identificação com o estranho [...].

Ora, não é possível encontrar o diverso nos dois porque, como ensina a filosofia, a dualidade reconduz à unidade, não sendo mais do que um desdobramento interno do 
mesmo, estabelecendo diferenças rigorosamente simétricas. Outro motivo é que "[...] na sua lógica interna [a dualidade é] a garantia de uma reversibilidade da diferença, de uma possibilidade genérica de remeter[se] para a unidade, o diferenciado para o indiferenciado" (WUNENBURGER, 1990, p. 34), o amor e o ódio, o claro e o escuro, o um e o outro são, no fundo, o mesmo, já que a representação do par se faz "[...] a partir de um simples eixo de repartição interna" (WUNENBURGER, 1990, p. 34). Se é certo que "[...] a simbólica da dualidade acha-se [...] ligada, na aritmologia tradicional, à alteridade e à heterogeneidade" (WUNENBURGER, 1990, p. 32), também é notável que, numa díade, o diverso, o outro não é realmente diferenciado de uma clivagem entre duas metades, sendo simplesmente uma divisão dele.

A alteridade, para se estabelecer, precisa do terceiro; só é possível diferenciar entre o mesmo e o outro se existir um terceiro elemento permitindo essa distinção. Para Wunenburger (1990, p. 48), a diferença somente se instala no intermundo, num "[...] terceiro elemento sobre o qual os distintos possam apoiar-se". Por que é tão difícil fazê-lo? Por que o terceiro excluído se impõe tão eficazmente? Mesmo contemporaneamente, quando virou moda reivindicar o terceiro incluído, é ainda o axioma identitário que rege o gesto humano. Com toda a sua incapacidade de conduzir à alteridade, ele é contumaz na sua força, observável não apenas na eficiência que conferiu à ciência e à tecnologia (o binarismo do código na informática é apenas sua expressão mais pitoresca), como na facilidade com a qual se recorre a ele nas classificações explicacionistas, férteis em variados terrenos, da moral à matemática, da física ao direito, da filosofia à informática. Duplas como bem/mal, falso/verdadeiro, claro/escuro, alto/baixo, fenômeno/coisa, ser/não ser, legal/ ilegal, zero/um, positivo/negativo, matéria/antimatéria são expressões da dupla fundante mesmo/outro, em que não cabe o verdadeiramente diferente, o terceiro. Uma resistência assim tenaz não se explica somente pela opção preferencial pelo reducionismo cartesiano e similares; ela é de ordem pulsional, ou seja, ela responde a um profundo temor.

O medo relaciona-se a algo existente fora do um; é o desconhecido que, no limite, faz nascer o sentimento do sagrado, como detalha Otto (1985). Entre 
o outro e o Outro há, é certo, uma distinção de grau, mas se trata sempre do terceiro sob o ponto de vista do mesmo, como afirma Todorov (1999, p. 3, grifos do autor): "Somente meu ponto de vista, segundo o qual todos estão lá e eu estou só aqui pode realmente separá-los e distingui-los de mim". Todorov mostrou bem, em sua narrativa sobre a conquista da América, como o outro enquanto segundo é, no fundo, o eu mesmo. Colombo, para Todorov, não conseguiu ver no índio nada além da imagem que já trazia dentro de si; o índio era apenas uma projeção do que Colombo já conhecia. Um segundo, uma duplicação, com valores inversos, do mesmo. De seu lado, o índio, no contato inicial com o europeu, sentiu medo, lançado que foi na estupefação total que se tem em vista do terceiro; estava não diante de uma projeção inversa de si mesmo, e sim diante do desconhecido, do Outro no seu limite mais extremo: o divino (CARRASCO, 2009).

O medo está, assim, na base da experiência da diferença absoluta que é o sagrado. No entanto, essa experiência do sagrado implica o sentimento de ser criatura diante do mistério do que é infinitamente grande, conforme Otto (1985), nas dimensões médias do cotidiano, a diferença absoluta não se estabelece, pois sempre há um ponto de referência ao qual é possível remeter o outro e, assim, no conforto de princípios lógicos bem conhecidos, trabalhar com nossas imagens favoritas, sejam de separação, de fusão ou de harmonização. Tanto separar quanto fundir dispensam o terceiro, sendo elas variações do mesmo. Por outro lado, se o outro é diferente do mesmo, já não temos dois, e sim três, pois é o intermediário que impede o corte binário ou a fusão monista, reconhecendo a pluralidade da harmonia conflitual, da simultaneidade do um, do dois e do três que Ihes dá consistência.

Compreendido como reunião em torno de uma imagem, o sucesso, para acontecer, precisa de um certo consenso, de uma redução das diferenças. Ora, sendo a redução das diferenças uma reação ao medo do diverso, o sucesso é antes resultado de um processo simbólico do que uma condição objetiva desta ou daquela obra. Assim, um ingrediente fundamental para que o sucesso se realize seria a solução do problema do medo ao diverso, sem a qual não é 
possível criar a identificação. Para que a imagem simbólica do sucesso aconteça, será necessária (embora, talvez, não suficiente) toda uma constelação, formada pelas homologias do sucesso que, a julgar pelo drama entre o um e o múltiplo rapidamente traçado acima, se fazem representar por tudo aquilo que deriva do gesto distintivo, fundante de todos os dualismos. Como exercício de reflexão sobre a relação material do sucesso com a alteridade, mapearemos nos filmes que mais atraíram público as constelações de imagens do mesmo ou do outro e verificaremos os princípios lógico-simbólicos que as regem.

\section{Um problema: detectar a imagem simbólica}

Imagem e movimento, ingredientes constituintes da linguagem do cinema, são formas de animação (injeção de alma), ou seja, de psicologização do abstrato, num processo de espaço-temporalização do pensamento. O cinema é, assim, uma das múltiplas maneiras que existem de colocar em imagem o que vai no psiquismo. Já o sucesso, sob a perspectiva do imaginário, como vimos, é uma imagem simbólica, independente, portanto, de ingredientes objetivos, mas totalmente sujeita a uma certa condição. Essa condição acontece ou não de acordo com o dinamismo do imaginário num dado ponto espaço-temporal.

Para desenhar a constelação de imagens, em vez de nos atermos aqui à visualidade da imagem no cinema, queremos nos debruçar sobre sua simbolicidade - para não dizer simbolismo, tentando evitar uma inadvertida remissão a algum sistema de códigos, a uma representação de um terceiro, de algo fora do aqui-agora.

O imaginário como um todo engolfa pensamento e imagem, sendo todo o pensamento uma imagem e toda a imagem uma forma de pensamento. Tanto a árvore de imagens de Wunenburger (2002) quanto a fita de Möbis são eficazes como analogia do sistema constituído pelo imaginário. No primeiro caso, temos a coerção pulsional das raízes arquetípicas perdendo força na medida em que sobe pelo tronco; ao chegar às folhas, cede espaço para a coerção exercida pelas condições externas, impostas pelos contextos sociais, culturais, políticos, históricos etc. No caso da conhecida metáfora da fita de Möbis, temos aparentemente dois 
lados que se revelam como um só; passa-se insensivelmente do exterior ao interior e vice-versa, sem que se interponham obstáculos materiais. Olhando-se a fita, vê-se o interior e o exterior dela, do mesmo modo que acreditamos apontar essa e aquela imagem simbólica num dado fenômeno; no entanto, enquanto condição de acontecimento é impossível dizer se a imagem é simbólica ou não, do mesmo modo que na experiência da formiguinha caminhando sobre a fita de Möbis não há lado de dentro e lado de fora.

Metodologicamente, a intenção de concentrar o estudo na simbolicidade mais do que na visualidade da imagem se resolverá pelo mapeamento de algo menos acabado que a própria imagem, daquilo que Durand (2016) indicou como schèmes figurativos. Esses são os responsáveis pela relação entre o corpo e a figuração, elo necessário quando se considera, com a tradição nascida em Bachelard, a materialidade da imaginação, materialidade esta que, nos estudos do imaginário, coloca o próprio corpo humano como nascedouro das imagens. Os schèmes, como imagens inacabadas, são também pensamentos embrionários. É essa a anterioridade fundadora do imaginário afirmada por Durand (2016), em que o schème "[...] faz a junção já não, como Kant pretendia, entre a imagem e o conceito, mas sim entre os gestos inconscientes da sensório-motricidade, entre as dominantes reflexas e as representações" (DURAND, 2016, p. 40, tradução nossa) ${ }^{4}$. Os três grandes schèmes anotados por Durand são derivados de três reflexos fundamentais do corpo humano e dão origem aos três grandes princípios lógicos que regem o imaginário: ao gesto postural, que é a tendência do bipedismo humano, corresponde o schème "[...] da verticalização ascendente e o da divisão quer visual quer manual" (DURAND, 2016, p. 40, tradução nossa)5, sob o comando da ação distintiva, formando constelações de imagens por isso chamadas de esquizomorfas e remetidas aos princípios lógicos de exclusão, contradição e identidade; o reflexo do engolimento se presentifica com o schème 
"[...] da descida e do acocoramento na intimidade" (DURAND, 2016, p. 40, tradução nossa $)^{6}$ impulsionado pela ação de misturar, dando origem ao nome de suas constelações de imagens: místicas. Os princípios lógicos, aqui, são de analogia e similitude. O reflexo rítmico se atualiza no schème da conexão, em que opostos que seriam separados numa constelação esquizomorfa ou que seriam misturados numa constelação mística são aqui harmonizados em constelações nomeadas de dramáticas. O princípio lógico é o da causalidade, unindo as contradições pelo tempo - daí o diacronismo das suas representações.

No entanto, deter-se nos schèmes não será suficiente, porque esse inacabamento da imagem a coloca numa condição bastante diferente (e, no limite, alheia) daquela palpável nos elementos, por assim dizer, concretos dos filmes estudados. Talvez fosse mais produtivo migrar para a ponta mais sólida, mais objetivável do fenômeno, constituída pelos sintemas, que são nada mais que os sintomas sociológicos da superestrutura mítica, como exemplo, o esquema da narração, as técnicas empregadas, a visualidade, o ritmo e a sonoridade das imagens, os objetos e cores das cenas etc. Ora, isso apenas mudaria o problema sem resolvê-lo. O estudo desses detalhes poderá responder várias perguntas sobre a organização estética do material estudado, sobre sua correlação com as várias éticas (suas derivações codificadas, como as políticas, as moralidades etc), mas não conseguirá dar pistas sobre a simbolicidade das imagens porque sua condição de acontecimento não é isolável para que se possa examiná-la. Assim se coloca o impasse: ou bem detemo-nos nos schèmes que, no entanto, são imagem inacabada, imagem ainda antes de ser imagem, o que pouco nos autorizará a extrapolar sobre o material estudado; ou bem nos limitamos à objetivação do filme que, por sua vez, pouco nos poderá dizer sobre o imaginário.

Vem em socorro a definição de imaginário legada por Thomas (1998, p. 15, tradução nossa): 
[...] a noção de 'imaginário' tomou um sentido inteiramente diferente: não mais é o termo oposto ao 'real' (e, portanto, uma espécie de erro, ou, na melhor das hipóteses, uma divagação amavelmente tolerada e deixada aos 'poetas'), mas um sistema, um dinamismo organizador de imagens que thes confere uma profundidade, ligando-as entre si. O imaginário não é, portanto, uma coleção de imagens somadas, um corpus, mas uma rede em que o sentido se encontra na relação. ${ }^{7}$

É eficaz a compreensão do imaginário não como conjunto, e sim como dinamismo de imagens porque afasta de imediato a oposição entre as duas configurações extremas do imaginário: a arquetipal e a fenomênica, o schème reduzido em variações, mas potencialmente infinito em sentidos e o sintema com suas infinitas variáveis e seus sentidos enrijecidos.

Opta-se, então, por ir e vir no percurso que vai dos vários sintemas objetivados no material estudado aos poucos schèmes fundadores, sem que os pontos de partida ou de chegada constituam uma axiologia.

\section{Entre a invariância polissêmica e a variação monossêmica}

O sucesso estrondoso é comum aos três filmes que ilustram esse exercício que, com muita hesitação, dada a despreocupação com encontrar o mito diretor da narrativa, chamamos de mitocrítica. Compreendendo, como vimos, o sucesso enquanto imagem simbólica pautada pela consensualidade e tendo na consensualidade, supostamente, uma significativa redução das diferenças, propomo-nos procurar em algumas peças culturais catalisadoras do sucesso as imagens que constelariam ou não com a redução das diferenças. Essas imagens foram recenseadas tanto a partir dos schèmes verbais, perceptíveis nos gestos que se constrói a ação, quanto dos sintemas, elencáveis a partir das figurações recorrentes.

No original francês: "[...] la notion d"imaginaire' a pris un tout autre sens : non plus le terme opposé à celui de 'réel' (et donc une sorte d'erreur, ou au mieux une divagation aimablement tolérée, et laissée aux 'poètes'), mas un système, un dynamisme organisateur des images, qui leur confère une profondeur en les reliant entre elles" (grifos do autor). 
Temos três histórias em que, sem constituírem o foco principal da narrativa, figuram os amores difíceis. Em Titanic, filme de James Cameron lançado em 1997, Rose (Kate Winslet), garota bela, culta e sensível, é pressionada pela mãe endividada (Frances Fisher) a desposar o rico, esnobe e covarde Caledon (Billy Zane), mas se apaixona por Jack (Leonardo Di Caprio), artista pobre, autêntico e destemido. Em ....E o vento levou, filme de Victor Fleming, lançado em 1939, a protagonista é Scarlett (Vivien Leigh), atrevida e bela, que, durante a Guerra da Secessão, se envolve amorosamente com Rhett (Clark Gable), mulherengo e aventureiro. Em Avatar, também de James Cameron, lançado em 2009, a história de amor é entre um humano, Jake (Sam Worthington) que participa de uma missão em uma lua extraterrestre, e uma humanoide, Neytiri (Zoe Saldana), com todas as dificuldades advindas do choque de civilizações e mesmo espécies diferentes.

A alteridade nessas histórias pode, sim, se encontrar no segundo que espelha o protagonista e que, à primeira vista, vem de um mundo outro: um Rhett maduro, independente, sem laços familiares caros, diante de uma juvenilíssima Scarlett mimada, cercada pela atenção dos pais; uma Rose aprisionada em convenções, atraída por um Jack livre delas; um humano Jake guiado pelo instinto militar, envolvido com uma humanoide Neytiri em profunda conexão com a natureza. Os mundos diferentes que se encontram nos três filmes replicam esses encontros com o outro; em Titanic, a alta sociedade e o populacho; em ...E o vento levou, os ianques e os confederados da Guerra da Secessão; em Avatar, humanos e humanoides. Temos o um, o outro, a diferença. E temos a grande cumplicidade do público, ou seja, o sucesso, de modo que essas diferenças foram de algum modo domesticadas.

Logo no início do filme Titanic, e para além da obviedade de se tratar de uma mídia visual, é convocado o olhar: o caçador de tesouros mostra para a sobrevivente Rose, 84 anos após o naufrágio, uma animação do acidente; Rose, por sua vez, com o olhar perdido através da janela do navio, vê o passado e começa a narrar a história, recuando para 1912. São emblemáticos também os momentos 
em que Jack, após ter deixado Londres, na proa do navio, vê o futuro olhando em direção à América; em que Rose também vê o futuro ao projetar uma vida de infelicidade ao lado de Caledon; em que o iceberg que destruiria o navio é avistado pela tripulação. Constelando com o ver está o separar (as classes de passageiros são distintas, o navio se separa do atracadouro, se distanciam os passageiros do navio e as pessoas que ficam para trás no cais) e o distinguir (os aposentos espaçosos e luxuosos de Rose em contraste com o cubículo de Jack dividido com outras três pessoas; a pobreza, a inteligência e a magnanimidade de Jack em contraste com a riqueza, o bitolamento e a covardia de Caledon). Esses schèmes surgem também na superfície dos sintemas (convés iluminado $x$ porão escuro, navio enorme $x$ barquinho pequeno) e na situação geral de Rose (aprisionada ao lado de Caledon, livre ao lado de Jack). A constelação de imagens esquizomorfas se confirma, finalmente, com o schème da distinção orquestrando a queda e o voo: Rose, desesperada, faz uma tentativa de suicídio ao tentar se jogar da proa do navio e a mesma Rose, só que feliz, com os braços abertos, também na proa, simula um voo, segura pela cintura pelas mãos protetoras de Jack.

Em ...E o vento levou, o casamento também vem como uma solução para problemas financeiros. No entanto, o schème dominante de Titanic é o da separação, de modo que o casamento aparece aí como uma falsa solução, sendo emblema não de junção, e sim de oposição. Já em ...E o vento levou, pontuado pelo schème do misturar, como veremos em seguida, o casamento soluciona não só a pobreza (é por dinheiro que Scarlett se casa com Frank e, logo em seguida à viuvez, com Rhett), como também soluciona os ciúmes (é ao ver o amado Ashley dedicado à Melanie que Scarlett decide se casar com o irmão desta). Ainda que realizados sem amor, os efeitos desses casamentos de Scarlett não são propriamente negativos.

O schème do misturar, além de presidir os três casamentos de Scarlett, se faz presente também nas constantes festas e reuniões, situações em que a dissolução dos limites entre o um e o outro se faz. Mesmo na guerra, com o pretexto de uma quermesse para arrecadar fundos, dança-se e come-se 
em grupo. Quando Rhett dança com Scarlett, a resistência da moça ("Jamais ouvirá de mim que o amo") apenas acentua a conjunção do par ("O senhor dança divinamente, capitão"). O sítio à cidade de Atlanta não impede Rhett de organizar festins com prostitutas. O sintoma social do schème misturar está, nesse filme, na matéria, na mais explícita de suas representações, a terra. No início do filme, o pai mostra à filha a importância da terra acima de tudo; no retorno à casa paterna, e diante da destruição generalizada, a terra é o arrimo e a esperança de Scarlett; ao ser repelida por Ashley, é a terra na mão fechada de Scarlett que Ihe renova a força e, logo depois, é jogada no rosto do ianque que Ihe cobra impostos abusivos. Finalmente, ao ver Rhett se afastar, quando descobre que no fundo o ama, sim, a Scarlett em desespero se acalma com a ideia de que, voltando mais uma vez à sua terra natal, vai clarear as ideias e encontrar um meio de recuperar a confiança do capitão. Outros sintemas vêm se unir ao da terra na constelação vetorizada por esse schème, como as joias, os presentes e mimos de Rhett a Scarlett, e a afirmação dela de que o dinheiro é a coisa mais importante do mundo. O esquife (da mãe de Scarlett, da filha, da cunhada) como côncavo homólogo à acolhida que a terra faz ao corpo a que a ela retorna é um sintema que vem sublinhar a lei da reversibilidade das imagens, cuja eficácia Bachelard (1990, 1999, 2001a, 2001b) mostrou na sua obra sobre os quatro elementos da imaginação material.

O schème da distinção comanda também o outro filme de Cameron dessa tríade, Avatar. É voando que os humanos saem da Terra e chegam a Pandora, é nas alturas das árvores gigantescas que os humanoides de Pandora provam sua agilidade, é cavalgando uma ave enorme que o humano Jack consegue provar aos humanoides Na>Vi que pode ser um deles. O voo, no que tem de subida e distanciamento, é veículo para a distinção. Os sintemas da distinção se multiplicam pelo filme, confirmando a constelação esquizomorfa: a paralisia de Jake $x$ seus movimentos ágeis quando encarna o avatar, o cientista inteligente $x$ o militar bronco, os humanos tecnicistas $x$ os humanoides conectados à natureza, o avançado $x$ o primitivo etc. 


\section{Conclusão: sucesso, a alteridade sem o outro}

É possível observar que a questão da alteridade subjaz aos três filmes, independente do argumento de suas narrativas. Conclui-se que tanto em Avatar quanto em Titanic predominam o gesto distintivo, com as imagens organizadas em pares de opostos simétricos, numa abordagem dualista da alteridade. Já em ...E o vento levou, o gesto místico é predominante, malgrado a guerra ser o pano de fundo da narrativa, com numerosas homologias de imagens da materialidade reconfortante. A negação da diferença conduz a abordagem monista da alteridade. Em quaisquer dos casos, é escamoteada a pluralidade, com a recusa da efetividade do Outro enquanto terceiro.

É notável como as profundezas do imaginário podem contradizer as imagens eflorescentes, aquelas que Wunenburger (2002) classifica como pertencentes à copa da árvore do sistema imaginário ${ }^{8}$, abundantes e visíveis a olho nu. Não seria a Guerra da Secessão, com o conflito armado entre brancos e pretos, entre o Sul escravagista e o Norte abolicionista, entre os ianques e os confederados, um pano de fundo perfeito para uma narrativa esquizomórfica, em que toda diferença é levada ao extremo, tratada como oposição? No entanto, a guerra propriamente dita quase não comparece; ouve-se falar dela, grita-se "os ianques estão chegando", foge-se dos ianques, os ianques ateiam fogo na cidade, mas será preciso esperar a segunda metade de ...E o vento levou para realmente ver um ianque. E então, Scarlett o mata, mas o gesto é defensivo, e, logo após, o vasculhamento dos bolsos do homem morto em busca de dinheiro e objetos de valor, em combinação com a aprovação do gesto pela cunhada e rival, Melanie, restabelece o conforto do regime místico, o regime da abundância material.

Em Avatar, desmentido semelhante ocorre. Nesse filme, comparece a figuração de um que poderia muito bem ser entendido como o terceiro, o avatar propriamente dito, que é um corpo postiço, à imagem e semelhança dos humanoides $\mathrm{Na}^{\prime} \mathrm{Vi}$, no qual os humanos encarnam para suas missões na 
atmosfera de Pandora, irrespirável para eles. Comandado pela mente humana, mas com todas as capacidades objetivas dos humanoides, o avatar seria o veículo perfeito para o terceiro excluído, fazendo a ponte entre os dois mundos. No entanto, as imagens de coincidência de opostos, características do schème do ligar, não comparecem para promover o balé das diferenças e desenhar uma constelação dramática. Impera antes a antítese polêmica que só se soluciona quando, presumivelmente, a julgar pelo final, o humano encarna definitivamente no corpo do avatar e se torna um $\mathrm{Na}^{\prime} \mathrm{Vi}$, confirmando que o regime dualista é, no extremo, o regime monista.

O um e o outro parecem ser ingredientes indispensáveis nas narrativas do sapiens. Mesmo a mais solipsista delas terá de encontrar variações sobre o mesmo para se desenrolar, aliadas a alguns ingredientes materiais que também parecem fixos no caso dos sucessos de cinema, como os grandes investimentos, os atores carismáticos e a realização com tecnologia de ponta. Mas ainda falta algo para que o sucesso seja garantido. A imagem visual é envolvente porque tem potencial especular; já o movimento é hipnoico, como especula Bachelard (1999) a respeito de nossa fixação do olhar no fogo flamejante. O cinema associa esses dois elementos, mas não é capaz de criar condições para o acontecimento simbólico. Quais seriam essas condições?

Não será difícil associar a sala escura a uma caverna iniciática e a tela iluminada a um altar, bastando isso para que seja reivindicada a atualização de uma sacralidade arcaica na experiência do cinema, redimindo-o da acusação de alienar massas erigida contra ele pelos estudos críticos da comunicação ${ }^{9}$. Entretanto, uma condição simbólica não tem explicação na alienação das mentes ou na possessão mítica, e sim na convergência entre as forças mobilizadas no imaginário e as imagens movimentadas no filme bem-sucedido. Há algo além da fórmula, algo que é o dispositivo anterior à fórmula: a emoção controlada, um mundo que se

"A atrofia da imaginação e da espontaneidade do consumidor cultural de hoje não tem necessidade de ser explicada em termos psicológicos. Os próprios produtos, desde o mais típico, o filme sonoro, paralisam aquelas faculades pela sua própria constituição objetiva" (HORKHEIMER; ADORNO, 1969, p. 163). 
desordena apenas para se reordenar. Essa ordem reproposta, se não for a do mundo, não provocará identificação. Talvez o sucesso desses filmes esteja não no fato de eles lançarem luz sobre fatos históricos ou projetarem possibilidades de nosso futuro, e sim em nos garantirem que tudo está como sempre esteve. Daí também a fertilidade dos estudos do imaginário no que tange ao diagnóstico psicossocial. O que um grande sucesso diz - seja um filme, um gênero musical, um meme, um vídeo que se torna viral - elucida as crenças de uma sociedade. Não é um arquétipo ativo que milagrosamente acalma as dores do mundo; não é um sistema político que perversamente semeia a desigualdade. É uma conjunção entre forças, algumas à mercê de nossas escolhas, outras imprevisíveis, tornando opaca toda tentativa explicacionista.

\section{Referências}

BACHELARD, G. A terra e os devaneios do repouso: ensaio sobre as imagens da intimidade. São Paulo: Martins Fontes, 1990.

A psicanálise do fogo. São Paulo: Martins Fontes, 1999.

. A terra e os devaneios da vontade: ensaio sobre a imaginação das forças. São Paulo: Martins Fontes, 2001a.

O ar e os sonhos: ensaio sobre a imaginação do movimento. São Paulo: Martins Fontes, 2001b.

BARROS, A. T. M. P. A fotografia no Instagram e as presenças do sagrado na contemporaneidade. In: CONGRESSO BRASILEIRO DE CIÊNCIAS DA COMUNICAÇÃO, 39., 2016, São Paulo. Anais eletrônicos... São Paulo: Intercom, 2016. Disponível em: <https://goo.gl/1rnLYo>. Acesso em: 5 jul. 2017. 
. Raízes dos estudos do imaginário: teóricos, noções, métodos. In: ARAUJO, D. C. ; CONTRERA, M. S. (Orgs.). Teorias da imagem e do imaginário. Brasília, DF: Compós, 2014. p. 50-78.

CAMPBELL, J. O herói de mil faces. São Paulo: Pensamento, 2007.

CARRASCO, D. (Ed.). Introduction. In: (Ed.). The history of the conquest of New Spain by Bernal Diaz del Castillo. Albuquerque: UNM Press, 2009. p. xi-xxvii.

CLIFT, J. D. ; CLIFT, W. B. The hero journey in dreams. New York: Crossroad, 1988.

DURAND, G. Campos do imaginário. Lisboa: Instituto Piaget, 1996.

. Les structures anthropologiques de l'imaginaire: introduction à I'archétypologie générale. Paris: Dunod, 2016.

FISCHER, R. M. B. O mito na sala de jantar: leitura interpretativa do discurso infanto-juvenil sobre a televisão. 1982. Dissertação (Mestrado em Educação) Fundação Getúlio Vargas, Rio de Janeiro, 1982. Disponível em: <https://goo.gl/ GyUnJ5>. Acesso em: 3 jun. 2017.

GOLDSTEIN, L. S. Becoming a teacher as a hero's journey: using metaphor in preservice teacher education. Teacher education quarterly, Ann Arbor, v. 32, n. 1, p. 7-24, Winter 2005. Disponível em: <https://goo.gl/3VFEvn>. Acesso em: 23 jun. 2017.

HAMILTON, J. F. Sand's la mare au diable, Awakening through "Evil" and the hero's journey. Nineteenth-Century French Studies, Lincoln, v. 36, n. 1-2, p. 45-60, FallWinter 2007. Disponível em: <https://goo.gl/HVGxDv>. Acesso em: 21 jun. 2017. 
HORKHEIMER, M.; ADORNO, T. A indústria cultural. O iluminismo como mistificação de massas. In: LIMA, L. C. (Org.). Teoria da cultura de massa. Rio de Janeiro: Saga, 1969. p. 163.

MCDONALD, W. C. The boar emblem in Gottfried's "Tristan". Neuphilologische Mitteilungen, Helsinki, v. 92, n. 2, p. 159-178, 1991. Disponível em: <https:// goo.gl/nigTzi>. Acesso em: 23 jun. 2017.

MORIN, E. O cinema ou o homem imaginário: ensaio de antropologia. Lisboa: Relógio D' Água, 1997.

OTTO, R. O sagrado: um estudo do elemento não-racional na ideia do divino e sua relação com o racional. São Bernardo do Campo: Imprensa Metodista, 1985.

THOMAS, J. Introduction aux méthodologies de l'imaginaire. Paris: Ellipses, 1998.

TODOROV, T. A conquista da América: a questão do outro. São Paulo: Martins Fontes, 1999.

VOGLER, C. A practical guide to Joseph Campbell's the hero with a thousand faces. [S.I.], 1985. Disponível em: <https://goo.gl/XchxW4>. Acesso em: 24 jun. 2017. The writer's journey: mythic structure for writers. London: Pan Books, 1996.

WUNENBURGER, J. J. A razão contraditória - Ciências e filosofias modernas: o pensamento complexo. Lisboa: Instituto Piaget, 1990.

La vie des images. Grenoble: PUG, 2002. 
WUNENBURGER, Jean-Jacques. As telas do sagrado ou o imaginário religioso da televisão. in: Intexto. Porto Alegre, UFRGS, set.-dez. 2017. p. 23-35.

submetido em: 10 jul. 2017 | aprovado em: 16 ago. 2017 